\title{
Correction to: Evaluating an isotonic aqueous formulation of Chaetomium globosum Kunze for the management of potato black scurf disease caused by Rhizoctonia solani Kuhn in India
}

\author{
Arunkumar $\mathrm{K}^{1}$ - S. Parthasarathy ${ }^{1,2} \cdot$ S. Harish ${ }^{1} \cdot$ Lingan Rajendran $^{1} \cdot$ T. Raguchander $^{1}$
}

Published online: 3 December 2021

(c) Società Italiana di Patologia Vegetale (S.I.Pa.V.) 2021

\section{Correction to: Journal of Plant Pathology \\ https://doi.org/10.1007/s42161-021-00971-6}

The original article was published with erroneous author information. The correct authorship should be noted and cited as it is now presented.

The original article has been corrected.

Publisher's Note Springer Nature remains neutral with regard to jurisdictional claims in published maps and institutional affiliations.

The original article can be found online at https://doi.org/10.1007/ s42161-021-00971-6.

Lingan Rajendran rajendran.1@tnau.ac.in

1 Department of Plant Pathology, Centre for Plant Protection Studies, Tamil Nadu Agricultural University, Coimbatore 641 003, India

2 Department of Plant Pathology, Amrita School of Agricultural Sciences, Amrita Vishwa Vidyapeetham, Coimbatore 642 109, India 